\title{
PV Cell Model by Single-diode Electrical Equivalent Circuit
}

\author{
Hyeonah Park*, Yong-Jung Kim** and Hyosung Kim ${ }^{\dagger}$
}

\begin{abstract}
This paper models PV cells as a single-diode electrical equivalent circuit. It extracts the parameters of the equivalent circuit through Thevenin-Norton transformation at three remarkable operation points such as open circuit condition, short circuit condition, and maximum power operating condition where the voltage and current are commonly provided by manufacturers. Since the slopes of the PV cell characteristic I-V curve at those operating points are associated with series resistance and shunt resistance of the electrical equivalent circuit, equivalent resistance at maximum power operation point, gradients of these three slops can be used as the boundary conditions to solve the unknown values of PV cell equivalent circuit. With this regards, this paper provides complete set of simultaneous equations to solve any type of PV cell models as single-diode equivalent circuit named by $\mathrm{K}$-algorithm. Proposed method is advantageous as it not only describes the I-V curve of initial PV cell products that manufacturers ensure by the characteristic datasheets, but also properly describes the deformed I-V characteristic curve of practically aged PV cells by just measuring the voltage and current values of at three remarkable operating points.
\end{abstract}

Keywords: PV power generation, EN50530, PV simulator, Si-Cr, Thin-film, PV cell modeling

\section{Introduction}

Solar energy is the basis of renewable energy which is so abundant that all the energy necessary in the whole world on the earth can be supplied by utilizing only $2 \%$ of it delivered to the earth's surface. Solar energy is a characteristic energy resource which does not cause any environmental problem since it is clean, can be obtained anywhere, and free of charge. Thanks to these advantages, the area of photovoltaic power generation has been growing rapidly every year.

PV cells in which semiconductors are used comprise several types such as the $\mathrm{Si}-\mathrm{Cr}$ type, the thin-film type, and the tandem type that combined these two types. PV cells have unique nonlinear I-V characteristic curves according to the types of material [1, 2]. PV cells' output characteristics vary with the weather conditions and are particularly dependent on irradiance levels and temperatures $[3,4]$.

The IEC regulation for the PV efficiency standard EN50530 specifies that the PV simulators should emulate the characteristics of both Si-Cr type and thin-film type PV cells so that they can be used to test overall efficiency of Power Conditioning Systems (PCS) for PV generation [5]. The standard requires to comply with not only the assessment of PCSs' static MPPT, but also the assessment of their dynamic MPPT. Thus, PV cells should be dynamically simulated even in the weather conditions

$\dagger$ Corresponding Author: Dev. of EE \& Control Eng., Kongju

National University, Korea. (hyoskim@kongju.ac.kr)

* Doorisystem Co., Korea. (parkha1106@gmail.com)

** Dev. of EE \& Control Eng., Kongju National University, Korea. (dream756@naver.com)

Received: February 19, 2016; Accepted: May 16, 2016 where the irradiance levels and temperatures change instantaneously. Errors in the characteristic curves of different PV cell simulators should not to exceed 1\% compared to the characteristic curve in the datasheet provided by the manufacturer. In particular, errors occurring in the maximum power operation range of $V_{M P P} \pm 10 \%$ should be minimized. [5]

In addition, simulations by PV cell modeling are also necessary to investigate economic feasibility of the installation of PV generators or to develop PCS control algorithms. To develop hardware simulators or to analyze software simulations for various types of PV cells, PV cell models that can be generally applied to diverse material characteristics and weather changes should be developed.

Electrical equivalent circuit based PV cell modeling algorithms are advantageous in that they facilitate the design of electronic controllers or the implementation of simulations. Representative papers on these algorithms have been published by A. Wagner [6], D. Sera [7], and M.Villalva [8] et al. Wagner algorithm is advantageous in that parameter extraction is completed by one calculation. However, large errors may occur if the material components of PV cells are changed as with the thin-film type, since it extracts parameters using numerical analysis methods aiming at $\mathrm{Si}-\mathrm{Cr}$ type PV cells [6]. The Sera algorithm has a characteristic of automatically finding all elements of equivalent circuits in an iteration method. But it has a convergence problem, because the unknown values that satisfy all the equations should be determined by a trial and error method by changing two repeating variables $R_{s}$ and $R_{s h}$ separately without a bound condition [7]. While the Villalva algorithm sets up an equation of $R_{s h}$ dependent on $R_{s}$ to make an $R_{s}-R_{s h}$ pair by increasing the value of $R_{s}$ with 
small steps in iteration loop. During the iteration, obtains the values of $\mathrm{I}(\mathrm{V})$ and $\mathrm{P}(\mathrm{V})$ where the domain is $\mathrm{PV}$ cell output voltage through calculations, and finds $P_{M A X}$ from the values. If the obtained $P_{M A X}$ and the $P_{M P P}$ in the manufacturer's datasheet do not coincide with each other, the above process will be tried again for the next candidate $R_{s}-R_{s h}$ pair until they coincide with each other. However, the Villalva algorithm has a defect that the user have to find out the value of the diode quality factor through trial and error by visually checking if it fits the I-V characteristic curve provided in the manufacturer's data sheet [8].

This paper presents a parameter extracting algorithm for single-diode electrical equivalent circuit based PV cell models through a method of setting up complete simultaneous equations. To extract the values of elements of PV cell electrical equivalent circuits, this paper applies the current-voltage values of 3-operating points under the Standard Test Condition (STC). Since the single-diode electrical equivalent circuit for PV cells has a total of four components, at least quaternary first order independent simultaneous equations are necessary. In the present study, five independent simultaneous equations are derived so that the degree of freedom of simultaneous equations becomes one dimension higher than that of the unknown quantities. Thus the diversity to select two equations for one element to obtain solutions is presented. In addition, it is explained that convergence conditions should be established for one element value and all solutions should be found through the iteration method.

The proposed modeling algorithm can validly establish electrical equivalent circuit models for PV cells having any semiconductor materials. The excellence of the proposed theory is proved by comparing the modeling performance of the proposed algorithm with the values in the manufacturer's datasheet and with the results of existing algorithms.

\section{Equivalent Circuit Parameterization}

\subsection{Single-diode electrical equivalent circuit}

PV cell manufacturer's datasheet presents the voltage and current values of the PV cell output terminals at 3 specific operating points under the standard test conditions (STC; Temperature $=25^{\circ} \mathrm{C}$, Irradiance $=100 \%$, Air Mass $=$ 1.5).

In other words, through the manufacturer's datasheet, the short-circuit current $\left(I_{s c}\right)$ under the condition where PV cell output terminals are short-circuited, the open-circuit voltage $\left(V_{o c}\right)$, under the condition where the PV cell output terminals are open, and the output terminal voltage and current $\left(V_{M P P}, I_{M P P}\right)$, when the PV cell outputs maximum power can be known.

As it can be seen from the electrical equivalent circuit in Fig. 1 and current characteristic equation in (1), the PV

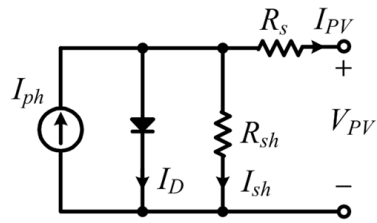

Fig. 1. Single-diode equivalent circuit of the PV cell

cells can be electrically modeled with five elements including diode constants $\left(I_{0}, v_{t}\right)$, photo current $\left(I_{p h}\right)$, series resistance $\left(R_{s}\right)$, and shunt resistance $\left(R_{s h}\right)[7]$.

$$
I_{P V}=I_{p h}-I_{0}\left(e^{\frac{V_{P V}+I_{P V} R_{s}}{n_{s} v_{t}}}-1\right)-\frac{V_{P V}+I_{P V} R_{s}}{R_{s h}}
$$

Here $v_{t}=\frac{a k T}{q}$

$I_{p h}:$ Current generated by solar energy [A]

$I_{0} \quad$ : Diode saturation current [A]

$v_{t} \quad$ : Ideal unit Cell thermal voltage [V]

$a \quad$ : Diode quality factor(1 1.5)

$k$ : Boltzmann's constant $\left(1.381 \times 10^{-23}\right)[\mathrm{J} / \mathrm{K}]$

$T$ : Kelvin Temperature at standard test condition $\left(=25^{\circ} \mathrm{C}+273.15\right)[\mathrm{K}]$

$Q \quad$ : Charge of the electron $\left(1.602 \times 10^{-19}\right)[\mathrm{C}]$

$n_{s}$ : Number of PV cells connected in series

$\mathrm{R}_{\mathrm{sh}}$ : Cell parallel(shunt) resistance $[\Omega]$

$\mathrm{R}_{\mathrm{s}} \quad$ : Cell series resistance $[\Omega]$

The values of photo currents can be estimated in proportion to irradiance levels. While, the values of the remaining four elements should be obtained by establishing quaternary first order independent simultaneous equations based on the open circuit voltage $\left(V_{o c}\right)$, short circuit current $\left(I_{s c}\right)$, and maximum output voltage/current $\left(V_{M P P} / I_{M P P}\right)$ which are the 3-operating points provided in the manufacturer's datasheet.

\subsection{Gradient of I-V characteristic curve}

Fig. 2 shows a typical PV cell $\mathrm{I}-\mathrm{V}$ characteristic curve and the concept of tangent gradients at the remarkable 3operating points. The tangent gradient at each operating point means incremental conductance which is an inverse number of the resistance value. In Fig. 2, the tangent

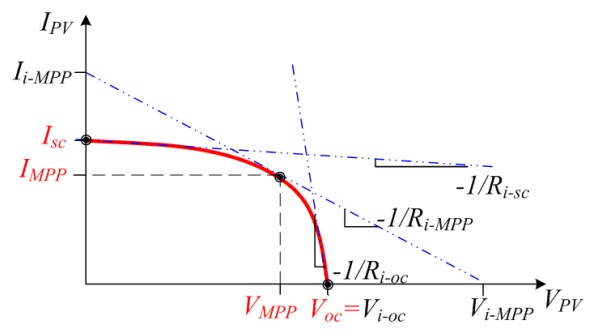

Fig. 2. Typical I-V curve in PV cells and tangent gradients 
gradient at the short-circuit operating point is defined as $1 / R_{i s c}$, the tangent gradient at the open circuit operating point is defined as $-1 / R_{i_{-} o c}$, and the tangent gradient at the maximum power point is defined as $-1 / R_{i} M P P$.

When the output terminal current of the PV cell equivalent circuit expressed by Eq. (1) is assumed to be the function of $I_{P V}=f\left(I_{P V}, V_{P V}\right)$, the tangent gradient at the 3operating points of the I-V characteristic curve can be obtained by differentiating the current characteristic equation with voltage as follows [7].

$$
\begin{gathered}
d I_{P V}=d I_{P V} \frac{\partial f\left(I_{P V}, V_{P V}\right)}{\partial I_{P V}}+d V_{P V} \frac{\partial f\left(I_{P V}, V_{P V}\right)}{\partial V_{P V}} \\
\frac{d I_{P V}}{d V_{P V}}=\frac{\frac{\partial f\left(I_{P V}, V_{P V}\right)}{\partial V_{P V}}}{1-\frac{\partial f\left(I_{P V}, V_{P V}\right)}{\partial I_{P V}}}
\end{gathered}
$$

If the tangent gradients at the short circuit operating point and maximum power operating point of the I-V characteristic curve are shown by applying (3), then (4), (5), and (6) will be used. Therefore, we can establish five simultaneous equations by applying current/voltage values at 3-operating points into (1) and (3) to solve five unknown values of the single diode equivalent model of PV cell.

$$
\begin{aligned}
& R_{i_{-} s c}=\left.\frac{d V_{P V}}{d I_{P V}}\right|_{\substack{V_{P V}=0 \\
I_{P V}=I_{s c}}} \\
& =\frac{1}{\left[\frac{I_{s c} R_{s}+I_{s c} R_{s h}-V_{o c}}{n_{s} v_{t}} e^{\frac{I_{s c} R_{s}-V_{o c}}{n_{s} v_{t}}}+\frac{1}{R_{s h}}\right]}+R_{s} \\
& R_{i_{-} o c}=\left.\frac{d V_{P V}}{d I_{P V}}\right|_{\substack{V_{P V}=V_{o c} \\
I P V=0}} \\
& =\frac{n_{s} v_{t} R_{s h}}{n_{s} v_{t}+\left(I_{s c} R_{s h}-V_{o c}+I_{s c} R_{s}\right)}+R_{s} \\
& R_{i_{-} M P P}=\left.\frac{d V_{P V}}{d I_{P V}}\right|_{\substack{V_{P V}=V_{M P P} \\
I_{P V}=I_{M P P}}} \\
& =\frac{1}{\left[\frac{1}{R_{s h}}+\frac{I_{s c} R_{s}+I_{s c} R_{s h}-V_{o c}}{n_{s} v_{t}} e^{\frac{V_{M P P}+I_{M P P} R_{s}-V_{o c}}{n_{s} v_{t}}}\right]}+R_{s}
\end{aligned}
$$

\subsection{Analysis of thevenin equivalent circuits}

The solutions of the above Eqs. (4), (5) and (6) can be obtained only when the boundary conditions have been given. When seen physically, the straight lines expressed as tangents at the 3 -operating points on the I-V curve in Fig. 2 can be regarded as characteristic equations of DC voltage sources having an internal impedance. Therefore, the values of $R_{i s c}, R_{i o c}$, and $R_{i M P P}$, which are the boundary conditions of Eqs. (4), (5) and (6) respectively can be found by converting electrical equivalent circuits for PV cells under individual operating conditions into Thevenin equivalent circuits.

\subsubsection{Thevenin equivalent circuits at short circuit condition}

If short circuit condition $V_{P V}=0$ and $I_{P V}=I_{s c}$ is appplied to the single-diode electrical equivalent circuit shown in Fig. 1, the equivalent circuit can be reconstructed as shown in Fig. 3(a). Since the diode equation is as shown by Eq. (7), the diode incremental resistance can be obtained by differentiating the diode current with the diode voltage as shown by (8).

$$
\begin{gathered}
I_{D}=I_{0}\left(e^{\frac{V_{D}}{n_{s} v_{t}}}-1\right) \\
\frac{d I_{D}}{d V_{D}}=\frac{I_{0}}{n_{s} v_{t}} e^{\frac{V_{D}}{n_{s} v_{t}}}
\end{gathered}
$$

Since the output terminal voltage becomes equal to $V_{P V}$ $=V_{D^{-}} I_{P V} \cdot R_{S}$ according to the Kirchhoff's law, it will become equal to $V_{D}=I_{S C} \cdot R_{S}$ if the short-circuit operating condition is applied. Therefore, the diode incremental resistance $R_{D-s c}$ at the short circuit operating condition is calculated as shown by Eq. (9).

$$
\frac{1}{R_{D_{-} s c}}=\left.\frac{d I_{D}}{d V_{D}}\right|_{V_{D}=I_{s c} R_{s}}=\frac{R_{s}}{R_{s h}\left(R_{s h}-R_{s}\right)}
$$

The internal resistance of the Thevenin equivalent circuit at the short-circuit operating condition is calculated as shown by (10) and the Thevenin equivalent circuit for PV cells is converted as shown in Fig. 4(a). Since the tangent gradient of the I-V characteristic curve becomes $-1 / R_{s h}$, the

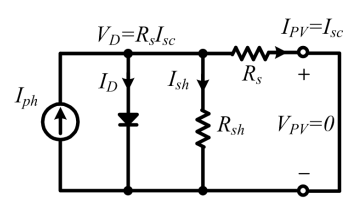

(a)

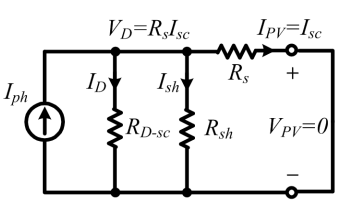

(b)
Fig. 3. Single-diode equivalent circuit of PV cell at short condition

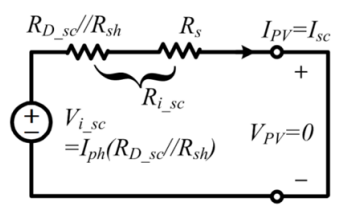

(a)

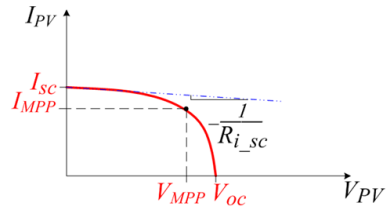

(b)
Fig. 4. Equivalent circuit of PV cell with voltage source at short condition 
inverse number of the Thevenin resistance becomes Eq. (10) at the short-circuit operating condition. Therefore, the boundary condition in Eq. (10) can be applied to Eq. (4) and developed in relation to as shown by Eq. (11).

$$
v_{t}=\frac{R_{i_{-} s c}=R_{D_{-} s c} / / R_{s h}+R_{s}=R_{s h}}{n_{s} \ln \left[\frac{I_{s c} R_{s}-V_{o c}}{\left(I_{s c} R_{s h}+I_{s c} R_{s}-V_{o c}\right)\left(R_{s h}-R_{s}\right)}\right]}
$$

\subsubsection{Thevenin equivalent circuits at open circuit condition}

If open circuit condition $V_{P V}=V_{o c}$ and $I_{P V}=0$ is applied to the single-diode electrical equivalent circuit shown in Fig. 1, the equivalent circuit can be reconstructed as shown in Fig. 5(a).

In this case, the diode incremental resistance can be obtained as shown by Eq. (12).

$$
\frac{1}{R_{D_{-} o c}}=\left.\frac{d I_{D}}{d V_{D}}\right|_{V_{D}=V_{o c}}=\frac{I_{s c} R_{s h}-V_{o c}+I_{s c} R_{s}}{\left(n_{s} v_{t}\right) R_{s h}}
$$

where, $R_{D_{-} o c}$ : Diode incremental resistance at open circuit condition

Therefore, at the open circuit condition, the internal resistance of the Thevenin equivalent circuit is calculated by Eq. (13) and the Thevenin equivalent circuit for the PV cell is converted as shown in Fig. 6.

$$
R_{D_{-} o c}=\frac{\left(n_{s} v_{t}\right) R_{s h}}{I_{s c} R_{s h}-V_{o c}+I_{s c} R_{s}}
$$

However, this solution is meaningless because it becomes trivial solution since the boundary condition in Eq. (15) and the gradient equation shown by Eq. (5) are the

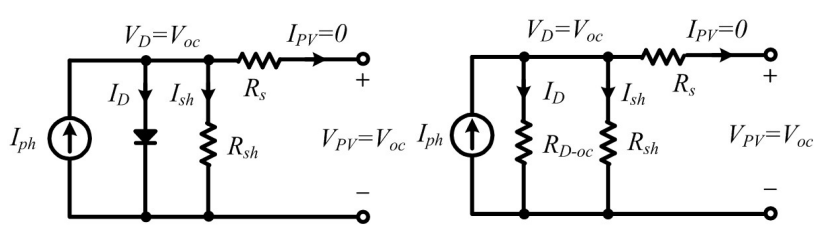

(a)

(b)

Fig. 5. Single-diode equivalent circuit of PV cell at open circuit condition

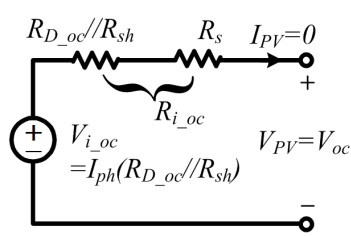

Fig. 6. Equivalent circuit of PV cell with voltage source at open condition same.

$$
R_{D_{-} o c} / / R_{s h}=\frac{n_{s} v_{t} R_{s h}}{n_{s} v_{t}+\left(I_{s c} R_{s h}-V_{o c}+I_{s c} R_{s}\right)}
$$

where, $R_{i_{-} o c}$ : Equivalent internal resistance at open circuit condition.

$$
\begin{aligned}
R_{i_{-} o c} & =R_{D_{-} o c} / / R_{s h}+R_{s} \\
& =\frac{n_{s} v_{t} R_{s h}}{n_{s} v_{t}+\left(I_{s c} R_{s h}-V_{o c}+I_{s c} R_{s}\right)}+R_{s}
\end{aligned}
$$

\subsubsection{Thevenin equivalent circuits at maximum power point}

If maximum power operating condition $V_{P V}=V_{M P P}$ and $I_{P V}=I_{M P P}$ is to the single-diode electrical equivalent circuit shown in Fig. 1, the equivalent circuit can be reconstructed as shown in Fig. 7(a). In this case, if the diode voltage $V_{D}$ $=V_{M P P}+I_{M P P} \cdot R_{s}$ is applied to Eq. (8), the diode incremental resistance will be obtained as follows;

$$
\frac{1}{R_{D_{-} M P P}}=\left.\frac{d I_{D}}{d V_{D}}\right|_{V_{D}=V_{M P P}+I_{M P P} R_{s}}=\frac{R_{s h}+R_{s}-R_{M P P}}{R_{s h}\left(R_{M P P}-R_{s}\right)}
$$

where, $\mathrm{R}_{\mathrm{MPP}}=\mathrm{V}_{\mathrm{MPP}} / \mathrm{I}_{\mathrm{MPP}}$

$R_{D M P P}$ : diode incremental resistance at MPP operation condition.

Therefore, at the maximum power operation condition, the internal resistance of the Thevenin equivalent circuit is calculated by Eq. (17) and the Thevenin equivalent circuit for the PV cell can be converted as shown in Fig. 8(a). Since the tangent gradient of the I-V characteristic curve becomes $-1 / R_{M P P}$, the inverse number of the Thevenin resistance can be calculated by Eq. (17) at the maximum power operating conditions. The boundary condition obtained here can be applied to Eq. (6) and developed in relation to $v_{t}$ as shown by Eq. (18).

$$
\begin{aligned}
& R_{i_{-} M P P}=R_{D_{-} M P P} / / R_{s h}+R_{s}=R_{M P P} \\
& v_{t}=\frac{V_{M P P}+I_{M P P} R_{s}-V_{o c}}{n_{s} \ln \left[\frac{n_{s} v_{t}\left(R_{s h}+R_{s}-R_{M P P}\right)}{\left(I_{s c} R_{s h}+I_{s c} R_{s}-V_{o c}\right)\left(R_{M P P}-R_{s}\right)}\right]}
\end{aligned}
$$

As such, two equations can be established in relation to

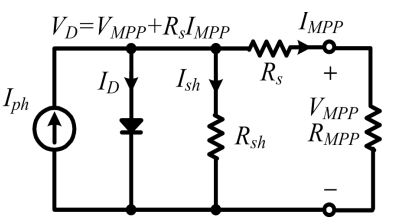

(a)

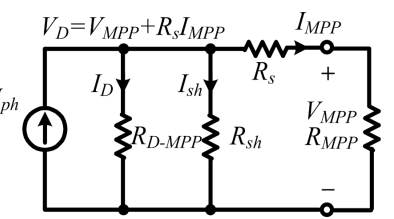

(b)
Fig. 7. Single-diode equivalent circuit of PV cell at MPP condition 


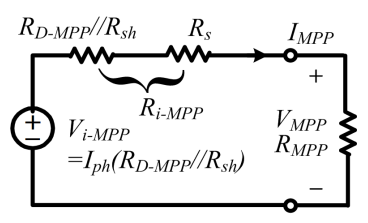

(a)

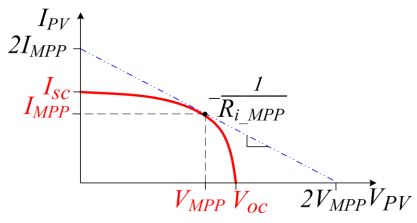

(b)
Fig. 8. Equivalent circuit of PV cell with voltage source at MPP condition

$v_{t}$ by analyzing the gradients of the I-V curve and the Thevenin equivalent circuit at the 3 -operating points. The above two equations related to $v_{t}$ are important formula which determine the performance of PV cell modeling. In the present study, the equation related to $v_{t}$ expressed by Eq. (11) is named K1-algorithm and the equation related to $v_{t}$ expressed by Eq. (18) is named the K2-algorithm.

\subsection{Analysis of the current characteristic equation at the 3-operating points}

Now, the equations to obtain the remaining four elements will be established by analyzing the characteristic current equation at the 3 -operating points.

\subsubsection{Thevenin Diode saturated current $\left(I_{0}\right)$}

The current characteristic equation set forth as Eq. (1) can be organized at the short circuit operating point as given by Eq. (19).

$$
I_{s c}=I_{p h}-I_{0}\left(e^{\frac{I_{s c} R_{s}}{n_{s} v_{t}}}-1\right)-\frac{I_{s c} R_{s}}{R_{s h}}
$$

In addition, the current characteristic equation set forth as Eq. (1) can be organized at the open circuit operating point as shown by Eq. (20).

$$
0=I_{p h}-I_{0}\left(e^{\frac{V_{o c}}{n_{s} v_{t}}}-1\right)-\frac{V_{o c}}{R_{s h}}
$$

If Eq. (20) is organized for $I_{p h}$, substituted into Eq. (19), it will become Eq. (21).

$$
I_{0}=\frac{I_{s c}\left(R_{s h}+R_{s}\right)-V_{o c}}{R_{s h}\left(e^{\frac{V_{o c}}{n_{s} v_{t}}}-e^{\frac{I_{s c} R_{s}}{n_{s} v_{t}}}\right)}
$$

Meanwhile, since $V_{o c}>>I_{s c} R_{s}$ as it can be seen from Fig. 9, $I_{s c} R_{s}$ can be omitted so that Eq. (21) can be approximated to:

$$
I_{0} \cong \frac{I_{s c}\left(R_{s h}+R_{s}\right)-V_{o c}}{R_{s h}} e^{-\frac{V_{o c}}{n_{s} v_{t}}}
$$

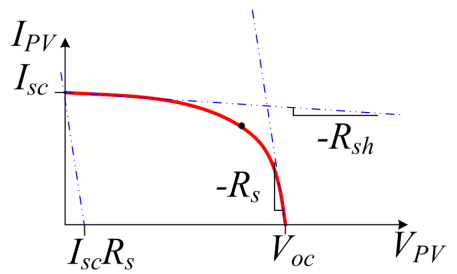

Fig. 9. Relationship between $V_{o c}$ and $I_{s c} R_{s}$.

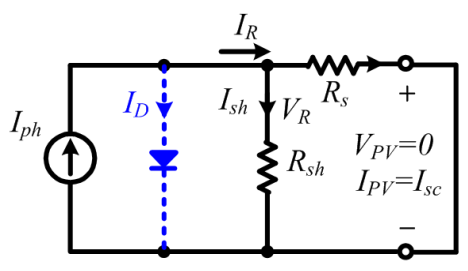

Fig. 10. Physical concept of Eq. (24)

\subsubsection{Photo current $\left(I_{p h}\right)$ values under STC conditions}

Meanwhile, if the $I_{0}$ induced in Eq. (22) is substituted into Eq. (20), then the equation solved for $I_{p h}$ will be:

$$
\begin{aligned}
& I_{p h}=I_{s c} \frac{R_{s h}+R_{s}}{R_{s h}}-\frac{I_{s c}\left(R_{s h}+R_{s}\right)-V_{o c}}{R_{s h}} e^{-\frac{V_{o c}}{n_{s} v_{t}}} \\
& I_{p h} \cong I_{s c} \frac{R_{s h}+R_{s}}{R_{s h}}
\end{aligned}
$$

The physical meaning of Eq. (24) is as shown in Fig. 10. That is, the diode current at short circuit operation can be neglected as (24).

\subsubsection{Shunt resistance $\left(R_{\text {sh }}\right)$}

Meanwhile, if the maximum power operating condition is applied to the current characteristic equation set forth as Eq. (1) and then the $I_{0}$ of Eq. (22) and the $I_{p h}$ of Eq. (24) are applied, the result will be as shown by Eq. (25).

$$
\begin{aligned}
I_{M P P}= & I_{s c} \frac{R_{s h}+R_{s}}{R_{s h}}-\frac{I_{s c}\left(R_{s h}+R_{s}\right)-V_{o c}}{R_{s h}} e^{-\frac{V_{M P P}+I_{M P P} R_{s}-V_{o c}}{n_{s} v_{t}}} \\
& -\frac{V_{M P P}+I_{M P P} R_{s}-V_{o c}}{R_{s h}}
\end{aligned}
$$

Meanwhile, if the boundary conditions are adopted for the left term of Eq. (6), the outcome will be as shown by Eq. (26).

$$
R_{M P P}=\frac{1}{\left[\frac{1}{R_{s h}}+\frac{I_{s c} R_{s}+I_{s c} R_{s h}-V_{o c}}{n_{s} v_{t}} e^{\frac{V_{M P P}+I_{M P P} R_{s}-V_{o c}}{n_{s} v_{t}}}\right]}+R_{s}
$$

If Eq. (26) is organized for exponential functions, the exponential function term included in Eq. (25) can be 
expressed as shown by Eq. (27).

$$
e^{\frac{V_{M P P}+I_{M P P} R_{s}-V_{o c}}{n_{s} v_{t}}}=\frac{n_{s} v_{t}\left(R_{s h}+R_{s}-R_{M P P}\right) R_{s}}{\left(I_{s c} R_{s h}+I_{s c} R_{s}-V_{o c}\right)\left(R_{M P P}-R_{s}\right)}
$$

Therefore, if Eq. (27) is applied to Eq. (25) to remove the exponential term, $R_{s h}$ will be as shown by Eq. (28).

$R_{s h}=\frac{\left(I_{s c}-I_{M P P}\right) R_{s}^{2}+\left(n_{s} v_{t}-I_{s c} I_{M P P}\right) R_{s}+R_{M P P}\left(V_{M P P}-n_{s} v_{t}\right)}{\left(I_{M P P}-I_{s c}\right) R_{s}+I_{s c} R_{M P P}-V_{M P P}-n_{s} v_{t}}$

Eq. (28) can be reorganized for easy expression as follows;

$$
R_{s h}=\frac{b_{0} R_{s}^{2}+b_{1} R_{s}+b_{2}}{-b_{0} R_{s}+b_{3}}
$$

where,

$$
\begin{aligned}
& b_{0}=\left(I_{s c}-I_{M P P}\right) \quad b_{1}=n_{s} v_{t}-I_{s c} I_{M P P} \\
& b_{2}=R_{M P P}\left(V_{M P P}-n_{s} v_{t}\right) \quad b_{3}=I_{s c} R_{M P P}-V_{M P P}-n_{s} v_{t}
\end{aligned}
$$

\subsubsection{Series resistance $\left(R_{s}\right)$}

So far, in order to obtain the $I_{p h}, I_{0}, v_{t}$, and $R_{s h}$ which are necessary for PV cell modeling, five independent simultaneous equations were established. Of those equations, two were used to obtain $v_{t}$ and three independent simultaneous equations can be applied to the remaining three unknown quantities. However, since the above simultaneous equations are in the form of transcendental functions, the solutions cannot be obtained analytically, but should be found through iteration. Here, $R_{s}$ is increased from 0 to the maximum level by a very small step under which condition $R_{s}$ is converged by iteration so that the solutions can be found.

Fig. 11 shows the concept to find conditions under which $R_{S}$ is converged by iteration. That is, the gradient of the straight line drawn from the origin that passes the maximum power operating point $\left(I_{M P P}, V_{M P P}\right)$ and that of the straight line drawn from the same origin that passes $\left(I_{s c}\right.$, $\left.V_{o c}\right)$ are almost the same. Therefore, since $V_{o c} \approx I_{s c} R_{M P P}$ can be regarded as being true, the exponential function of Eq. (27) can be approximated as shown by Eq. (30).

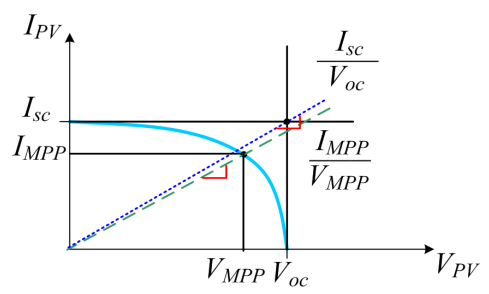

Fig. 11. Concept of approximation to find $R_{s}$ convergence conditions

$$
\begin{aligned}
e^{\frac{V_{M P P}+I_{M P P} R_{s}-V_{o c}}{n_{s} v_{t}}} & \approx \frac{n_{s} v_{t}\left(R_{s h}+R_{s}-R_{M P P}\right)}{I_{s c}\left(R_{s h}+R_{s}-R_{M P P}\right)\left(R_{M P P}-R_{s}\right)} \\
& =\frac{n_{s} v_{t}}{I_{s c} R_{M P P}}=\frac{n_{s} v_{t} I_{M P P}}{I_{s c} V_{M P P}}
\end{aligned}
$$

Therefore, if Eq. (31) is substituted into Eq. (26) and developed for $R_{s h}$, the outcome will be as shown by Eq. (32).

$$
R_{s h}=\frac{a_{0}-a_{1} R_{s}}{a_{1}}
$$

Here, $a_{0}=-V_{M P P}+\frac{n_{s} v_{t} I_{M P P} V_{o c}}{I_{s c} I_{M P P}}, a_{1}=I_{M P P}-I_{s c}+\frac{n_{s} v_{t} I_{M P P}}{V_{M P P}}$

Therefore, if Eq. (29) and Eq. (32) are assumed to be the same, $R_{s}$ will be approximated into Eq. (33).

$$
R_{s}=\frac{a_{0} b_{3}-a_{1} b_{2}}{a_{1} b_{1}+a_{0} b_{0}+a_{1} b_{3}}
$$

\subsection{Flow chart}

Fig. 12 shows flow-chart for the extraction of the electrical equivalent circuit parameters of PV cells. At the beginning, $R_{s}$ try begins with 0 and $v_{t}$ is initialized into Eq. (34).

Within the iteration routine, $R_{s}$ try is increased step by step by the small value set up by Eq. (35) while calculating the values of the unknown quantities established earlier. If the size of the difference between the value obtained within the iteration routine and the value obtained through Eq. (33) becomes smaller than the threshold value(here 0.0001 ), the solution will be regarded to have been obtained and the iteration will be terminated.

$$
v_{t}=\frac{1.25 k T}{q}
$$

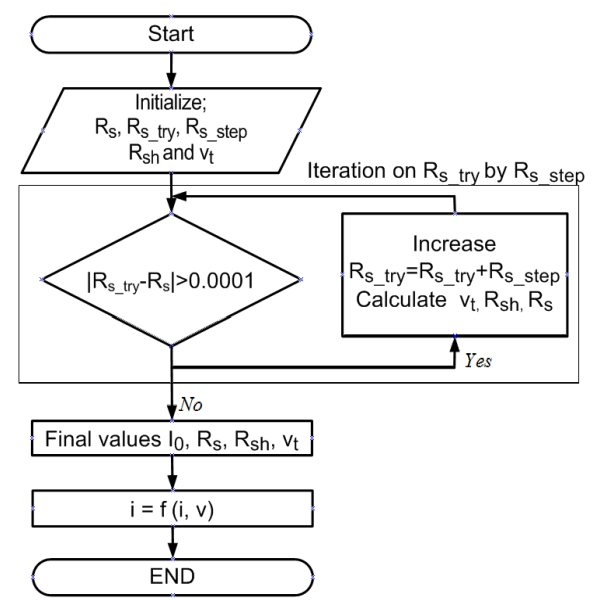

Fig. 12. Flowchart of parameter extraction 


$$
R_{s_{-} \text {step }}=\frac{\frac{V_{o c}-V_{M P P}}{I_{M P P}}}{1000}
$$

\section{PV Cell Modeling}

\subsection{PV cell modeling under STC conditions}

Standard EN50530 stipulates that PV cell modeling errors integrated along VMPP $\pm 10 \%$ which is the operating range of MPPT should be less than $1 \%$. In the present study, to assess the performance of existing algorithms and that of the proposed K-algorithm, the algorithms were simulated using the samples presented in Table 1.

The I-V characteristic curves and integration errors resulting from existing algorithms and the proposed Kalgorithm are shown as graphs in Fig. 13 and Fig. 14 and the integration errors were obtained as shown in Table 2. In case of Si-crystal type PV cells, Villalva algorithm showed best result and the characteristic curve in the datasheet was closely simulated. However, when the Vilallva algorithm was applied to thin film type PV cells the algorithm was

Table 1. Manufacturers Datasheets of PV Cell Specimen

\begin{tabular}{c|c|c}
\hline PV Cell & AT50 & X73-A \\
\hline Parameter & $\begin{array}{c}\text { Air Therm Solar } \\
\text { technik }\end{array}$ & $\begin{array}{c}\text { Inventux Technologies } \\
\text { AG }\end{array}$ \\
\hline Manufacturers & 3.3 & 1 \\
\hline $\mathrm{I}_{\mathrm{sc}}[\mathrm{A}]$ & 21.5 & 134 \\
\hline $\mathrm{V}_{\mathrm{oc}}[\mathrm{V}]$ & 2.86 & 0.7 \\
\hline $\mathrm{I}_{\mathrm{MPP}}[\mathrm{A}]$ & 17.5 & 105 \\
\hline $\mathrm{V}_{\mathrm{MPP}}[\mathrm{V}]$ & 50 & 73 \\
\hline $\mathrm{P}_{\mathrm{MPP}}[\mathrm{W}]$ & &
\end{tabular}

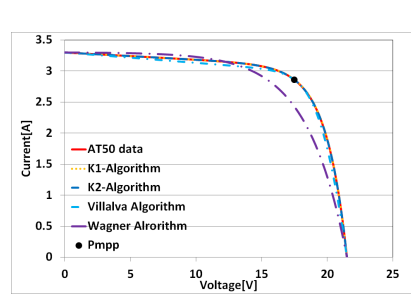

(a)

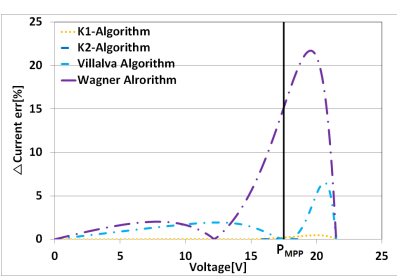

(b)
Fig. 13. Comparison of $\mathrm{I}-\mathrm{V}$ curve $\&$ integration error for AT50(Si-Cr type)

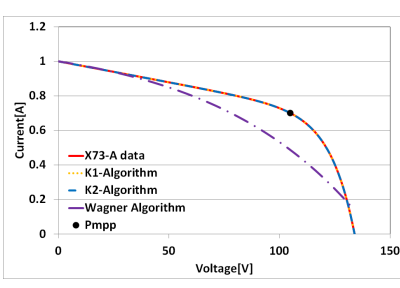

(a)

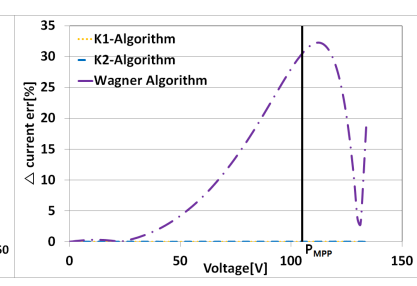

(b)
Fig. 14. Comparison of $\mathrm{I}-\mathrm{V}$ curve \& integration error for X73-A(Thin-film type) not converged and solutions could not be obtained in some cases. Although the Wagner algorithm can implement a I-V characteristic curve for a Si-crystal type by one calculation, it generated severe errors when PV cell materials have been changed as with thin film types. The proposed Kalgorithms showed smaller processing time of the iteration routine for obtaining equivalent model parameters and smaller integration errors compared to existing algorithms. Among them, K2-algorithm was shown to be generally the most excellent in terms of the number of iteration and error integration.

\subsection{PV cell model according to weather condition}

Fig. 15 and Fig. 16 show the characteristic curve of the proposed PV cell model according to temperatures and insolation.

As can be seen from Fig. 15, $I_{s c}$ decreases almost linear proportionally under conditions when insolation decreases where the temperature is constant. Under conditions where insolation is constant as shown in Fig. 16, it can be seen that when the temperature drops, whereas $V_{o c}$ increases, $I_{s c}$

Table 2. Comparison Result of Each Modeling Algorithm for Several PV Panels (Iteration number and error integration)

\begin{tabular}{c|c|c|c|c}
\hline \multirow{2}{*}{ PV Cell } & \multicolumn{2}{|c|}{ AT50 } & \multicolumn{2}{c}{ X73-A } \\
\cline { 2 - 5 } & $\mathrm{N}_{\text {Iter }}$ & $\mathrm{I}_{\text {err }}$ & $\mathrm{N}_{\text {Iter }}$ & $\mathrm{I}_{\text {err }}$ \\
\hline K1 & 964 & 0.52 & 100 & 0.004 \\
\hline K2 & 11 & 0.07 & 13 & 0.015 \\
\hline Villalva & 3524 & 0.01 & \multicolumn{2}{|c}{ Fail* } \\
\hline Wagner & 1 & 14.43 & 1 & 30.4 \\
\hline
\end{tabular}

$\mathrm{N}_{\text {Iter }}$ : Iteration number of I-V curve realization

$\mathrm{I}_{\text {err }} \quad$ : Integral error in voltage range of $\mathrm{V}_{\mathrm{PV}}=\mathrm{V}_{\mathrm{MPP}} \pm 10 \%$

* $\quad \mathrm{R}_{\mathrm{sh}}$ becomes infinite in one loop

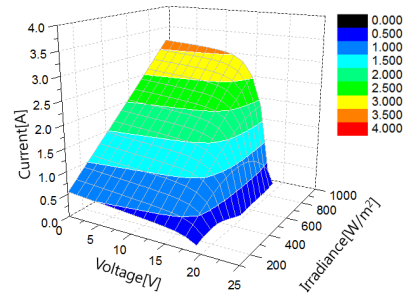

(a) $\mathrm{V}_{\mathrm{PV}}-\mathrm{I}_{\mathrm{PV}}$ - Irradiance

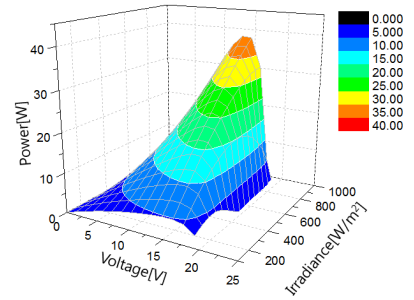

(b) $\mathrm{V}_{\mathrm{PV}}-\mathrm{P}_{\mathrm{PV}}$ - Irradiance
Fig. 15. Characteristic curve according to irradiance level.

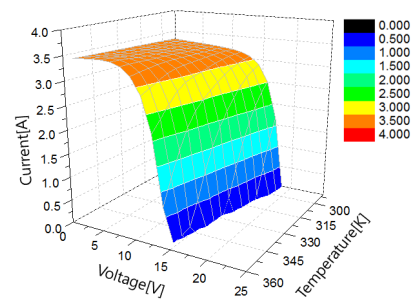

(a) $\mathrm{V}_{\mathrm{PV}}-\mathrm{I}_{\mathrm{PV}}-$ Temperature

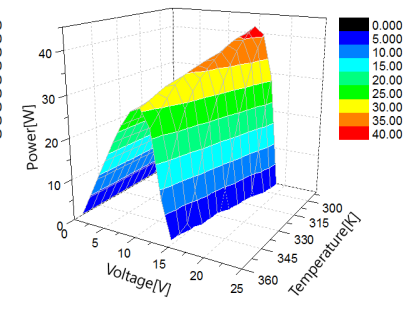

(b) $\mathrm{V}_{\mathrm{PV}}-\mathrm{P}_{\mathrm{PV}}-$ Temperature
Fig. 16. Characteristic curve according to temperature. 


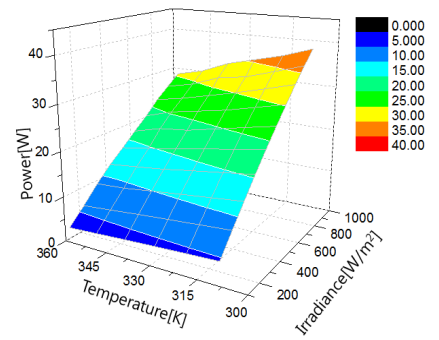

Fig. 17. Maximum power points according to irradiance level and temperature.

tends to decrease at rates relatively smaller than those of voltage. Fig. 17 shows the maximum power that can be outputted by the PV cell according to temperatures and insolation. As can be seen from the results of simulations, maximum power tends to increase when insolation is larger and temperatures are lower. The proposed PV cell model instantaneously informs the maximum power that can be outputted by the relevant PV cell under diverse environmental conditions in terms of temperatures and insolation. This information enables instantaneous assessment of the performance of MPPT controllers of PCS.

\section{Conclusion}

In the present study, a PV cell modeling algorithm based on electrical equivalent circuits that have clear physical meaning and easiness of implementation was presented. The proposed algorithm can extract electrical equivalent circuit element values validly for PV cells having any materials and enables modeling of even those PV cells that have been aged for long periods of time by only measuring the deformed voltage and current values at the three remarkable operating points.

The modeling performance of the proposed algorithm was compared with values in manufacturer datasheets and the results of modeling by existing algorithms to demonstrate the excellence of the proposed theory. The developed PV cell model can be utilized in determining voltage-current reference values when PV simulators are made as hardware and when PV power generation related simulation programs are established as software.

\section{Acknowledgements}

This work was supported by the research grant of the Kongju National University in 2014.

\section{References}

[1] Simon Lineykin, Moshe Averbukh and Alon Kuperman, "Issues in Modeling Amorphous Silicon Photovoltaic Modules by Single-Diode Equivalent
Circuit," IEEE Transactions on, Industrial Electronics, vol.61, no.12, pp. 6785-6793, Dec. 2014.

[2] Shu-Xian Lun, Ting-Ting Guo and Cun-jiao Du, "A New Explicit I-V Model of a Silicon Solar Cell Based on Chebyshev Polynomials," Solar Energy 119, pp. 179-194, 2015.

[3] Alberto Dolara, Sonia Leva and Giampaolo Manzolini, "Comparison of Different Physical Models for PV Power Output Prediction," Solar Energy 119(2015), pp. 83-99, 2015.

[4] Satarupa Bal, Anup Anurag, Mrutyunjaya Nanda and Suman Sourav, "Comprehensive Analysis and Experimental Validation of an Improved Mathematical Modeling of Photovoltaic Array," Advances in power Electronics, Vol. 2015, Article ID 654092, 11pages, 2015.

[5] IEC EN50530 Standard for Overall efficiency of photovoltaic inverters, CENELEC, Stassart 35, B1050 Brussels.

[6] Christian Bendel and Andreas Wagner, "Photovoltaic Measurement Relevant to the Energy Yield," in Proc. WCPEC-3 World Conference on Photovoltaic Energy Conversion, Osaka, Japan, pp. 1 - 4, May 2003.

[7] Dezso Sera, Remus Teodorescu and Pedro Rodriguez, "PV Panel Model Based on Datasheet Values," in Proc. on ISIE07, pp. 2392 - 2396, 2007.

[8] Marcelo Gradella Villalva, Jonas Rafael Gazoli and Ernesto Ruppert Filho, "Compregensive Approach to Modeling and Simulation of Photovoltaic Arrays," IEEE Trans. on PE, Vol. 24, No. 5, pp. 1198-1208, May 2009.

[9] Hyun-Ah Park, Hyosung Kim, "PV cell modeling on single-diode equivalent circuit," Conference Records on IEEE/IECON2013, CD ROM, 12 Nov. 2013.

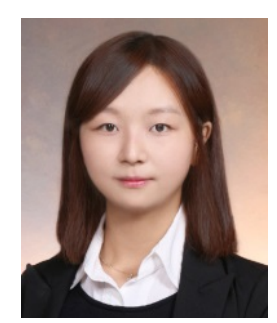

Hyeonah Park She received B.S. and M.S. degrees and quit doctoral course after $1^{\text {st }}$ semester in the Division of Electrical \& Electronic Engineering from Kongju National University in Korea on 2013, 2015, 2016 respectively. After quit doctoral course, she is employed at Doorisystem Co., Korea, where she participated in the high tech road safety project. She is interested in disaster prevention, traffic safety system.

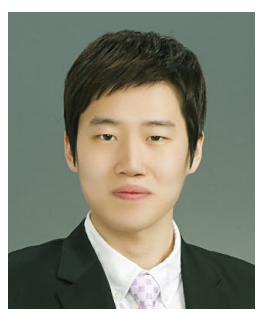

Yong-Jung Kim $\mathrm{He}$ received B.S degree and M.S degree in Control \& Measurement Engineering from Kongju National University in Korea on 2014 and 2016 respectively, where he is currently working toward the Ph.D. degree in power electronics. He is 
interested in renewable energy, DC power systems and grid-connected inverters.

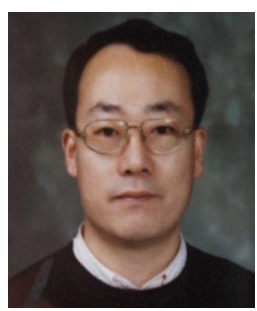

Hyosung Kim He received B.S. and M.S. degrees in the Dept. of Elec. Eng. from Seoul National University in Korea on 1981 and 1983, respectively. He received Ph.D. degree in the Dept. of Elec. Eng. from Chungbuk National University in Korea on 1995. From 1982 to 1986 , he was employed at Tong-Yang Cement Mfg. Co., Korea, where he participated in factory automation and energy saving project. From 1996 to 1997, he was a visiting scholar in the Dept. of Elec. Eng. at Okayama University, Japan. From 2000 to 2001, he was an associate research professor in the Institute of Energy Technology at Aalborg University, Denmark. From 1997 to present, he is a tenured professor in the school of EE and Control Eng. at Kongju National University, Korea. He is interested in Power Quality, Static Compensators, Renewable energy, and DC Distribution Systems. 